\title{
A Novel Device of True Triaxial Apparatus for Making Layered Sand Specimen
}

\author{
Jinqiao Liu ${ }^{1,2}$, Xuefeng $\mathrm{Li}^{2, *}$ and Hongyan $\mathrm{Li}^{1}$ \\ ${ }^{1}$ College of Mechanical Engineering, Ningxia University, Yinchuan 750021, China. \\ ${ }^{2}$ Solid Mechanics Institute, Ningxia University, Yinchuan 750021, China. \\ ${ }^{*}$ Corresponding author
}

\begin{abstract}
Due to the anisotropy of sand, the sand will inevitably lead to different patterns of failure under principal stress axes rotation condition. It is necessary to research sand with different deposition angles. However, the existing sand sample preparation device of true triaxial apparatus only can prepare the specimen with 90 degree of deposition angle, which cannot meet the need for the true triaxial test to research the sand anisotropy. In this paper, I summarized the development of true triaxial sand sample preparation device, considering the limitations of previous designs, and introducing a novel visual specimen preparation device for true triaxial tests that can make the different deposition angles of layered sand. This visual specimen preparation device consists of three parts, a transparent bucket, a small funnel and a base with adjustable angle, which can prepare the sand sample with 15 degree, 30 degree, 45 degree, 60 degree, 75 degree and 90 degree.
\end{abstract}

Keywords - true triaxial test; sand specimen preparation device; different deposition angles; visual

\section{INTRODUCTION}

As a common engineering material, The sand is widely distributed on the earth's surface, and it is closely related to human life. The sand is a kind of three phase complex, including solid, liquid and gas. It is a natural geological body with discontinuity, heterogeneity, anisotropy and non-linearity. In the real geotechnical environment, the arrangement of natural sand grains presents random, disorder and chaos. True triaxial sand sample preparation device is indispensable to provide the sand sample for true triaxial test. The preparation quality of true triaxial sand sample is the prerequisite to determine whether the true triaxial test is smooth or not. On the other hand, the development of sand sample with different deposition angles can provide a guarantee for researching constitutive relation of sand by the true triaxial test[1].

\section{WORKING PRINCIPLE AND STRUCTURE OF SAND SPECIMEN PREPARATION DEVICE}

The triaxial test is divided into the conventional triaxial test and the true triaxial test. The stress of the conventional triaxial test is axisymmetric on the X-Y plane, that is $\sigma_{2}=\sigma_{1}$, while the stress of the true triaxial test is independently loaded from the three directions of $\mathrm{X}, \mathrm{Y}$ and $\mathrm{Z}$ to the six surfaces of the sand sample, and it can simulate the real stress state of sand in nature. The relationship between the three principal stress sizes are $\sigma_{1}>\sigma_{2}>\sigma_{3}$. Therefore, the sand sample preparation device and the sand sample of the conventional triaxial test are cylindrical, but the sand sample preparation device and the sand specimen for the true triaxial test normally have a cubic shape or brick shape[3].

\section{A. GDS True Triaxial Sand Specimen Preparation Device}

The main function of the sand sample preparation device is to fix the scattered sand into a stable cuboid shape. The true triaxial test requires the shape of specimen that is cuboid or cube, and the top and bottom of the sand sample preparation device are all through, consisting of fixed plates and suction pipes. The material is usually made of carbon steel or cast iron, and most of them are made up of four removable fixed plates, and also a few of them are made up of two $\mathrm{Z}$ - shaped plates.

The present Global Digital Systems (GDS) true triaxial sand sample preparation device is shown in Figure I. Its sand specimen is $75 \mathrm{~mm}^{*} 75 \mathrm{~mm} * 150 \mathrm{~mm}$. Its internal volume size is $76 \times 76 \times 176 \mathrm{~mm}^{3}$, which is made up of four alloy steel plates, and each alloy steel plate has four tapping holes. Because sand is easily moved by external force, before preparing the sample, it is necessary to carry out the vacuum pumping operation and fix the shape of sand. The first step, we put the rubber membrane, about $0.4 \mathrm{~mm}$ thick, on the inner wall of the specimen preparation device. The second step, we connect the vacuum pump and the suction pipe (it is on the side of the device) for vacuuming treatment, so that the rubber membrane is tightly attached to the inner wall of the device. Finally, we pour the sand into the rubber membrane with funnel.
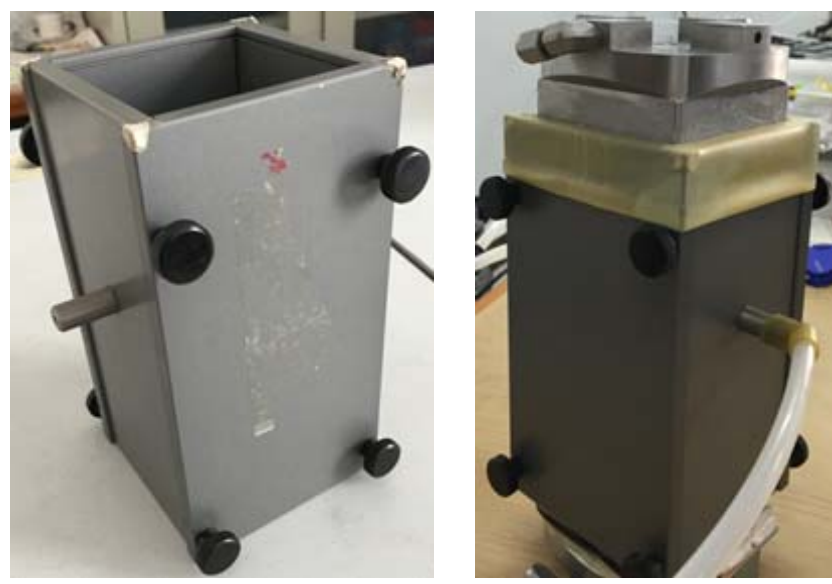

FIGURE I. GDS TRUE TRIAXIAL SAND SAMPLE PREPARATION DEVICE

In nature, without external force, the sand can keep the static granular like solid, but when there is an external force, 
the sand will flow along with the force like liquid[9]. The present, at home and abroad, the design of the true triaxial sand sample preparation device only can prepare the sand sample with 90 degree of deposition angle, which can not meet the need for the true triaxial test to research the anisotropy of sand. And it is necessary to design a kind of sand sample preparation device that can prepare different deposition angles of stratified sand to provide a guarantee for researching the sand anisotropy.

\section{B. Frozen Sand Specimen}

Due to the heterogeneity and anisotropy of sand, and during the specimen preparation, the sand sample must be wrapped with rubber membrane. It is more difficult to prepare sand sample with different deposition angles.

The First National Conference on Constitutive Theory for Geomaterials, some experts have proposed the preparation of sand sample by freezing method.

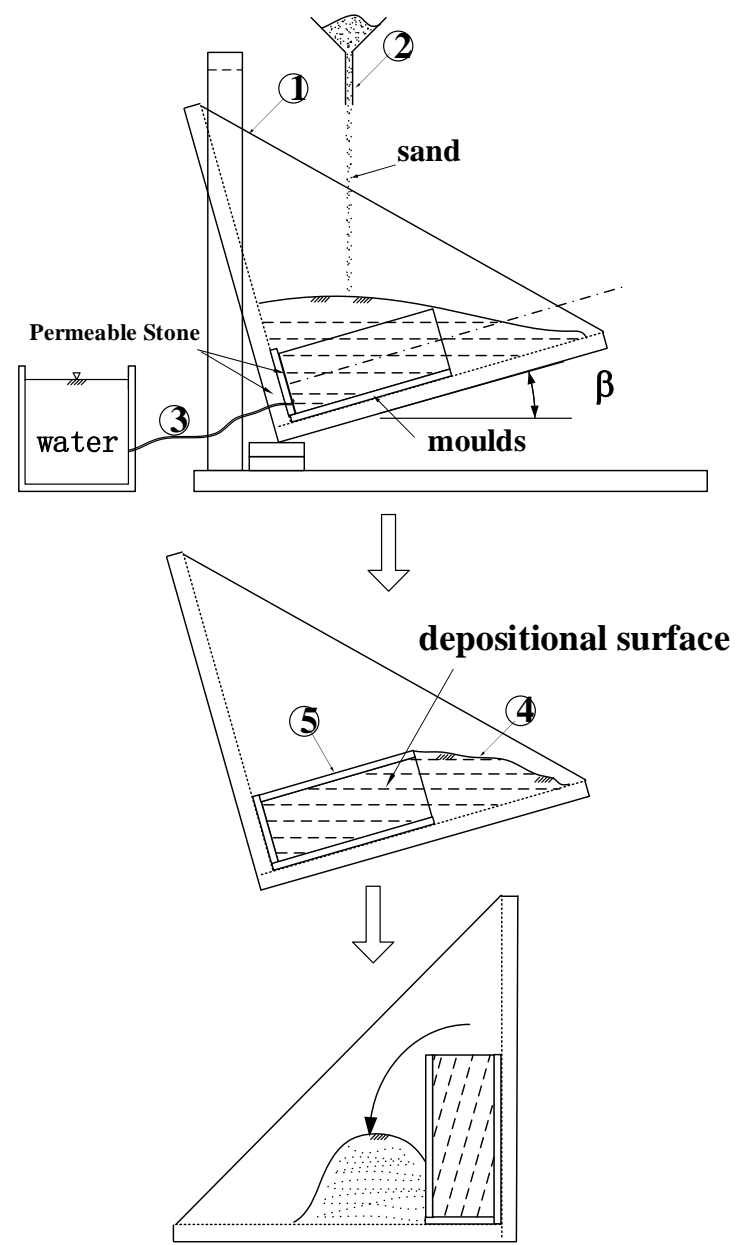

1. MOLD 2. FUNNEL 3. PIPE 4. DEPOSITIONAL SURFACE 5. FIXED PLATE

FIGURE II. PREPARATION OF SAND SAMPLE BY FREEZING METHOD

This operation is shown in Figure II, The first step, we placed the specimen, without rubber membrane, on the mold with a tilted angle of beta. The second step, we removed the fixed plate which is on the upper side of the device, so that the device keeps a certain inclination angle with the horizontal plane. The third steps, we use the funnel evenly to pour the sand into the device. Meanwhile, we open the water pipe and slowly pour a little of water into the bottom of the device to keep the sand wet. The fourth steps, after the sand is filled with the device, we installed the fixed plate which was removed before, cleaned up the excess sand, and frozen the prepared specimen. The fifth steps, we put the rubber membrane on the frozen specimen for thawing maintenance. Although this method has achieved the requirement of preparing sand sample with multiple deposition angles, it has not been popularized because of the cumbersome operation steps and longer operation time.

\section{Multi-angles Sand Sample Preparation Device}

Wang Junjie, Chongqing Jiaotong University, designed a multi-angles and non-horizontal layered sand sample preparation device. As shown in Figure III, the sand is placed in a hollow box body, and the sand is pressed into multi-angles layered sand by a pressure plate with a inclined angle. This device has realized the purpose of preparing the tilted sand specimen. However, for sand with fluidity, it has not yet been able to solve the accuracy of sand sample stratification and avoid the problem of sand disturbance[8].

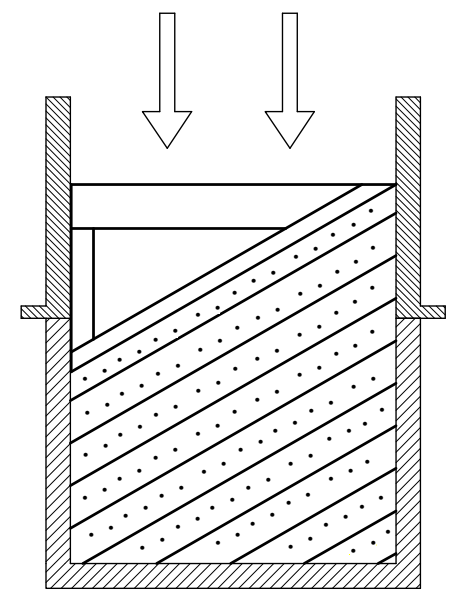

FIGURE III. A MULTI-ANGLES NON-HORIZONTAL LAYERED SOIL SAMPLE MAKING DEVICE

In view of the above analysis, it is known that the preparation quality of the true triaxial sand sample is the prerequisite to determine whether the true triaxial test is smooth, and the research of the sand sample with different deposition angles can provide a guarantee for the constitutive relationship of the true triaxial test.

\section{The Structure Design of THE Novel DeVICE For MAKING LAYERED SAND SPECIMEN}

A novel device of true triaxial apparatus for making layered sand specimen, as shown in Figure IV, consists with a transparent bucket, a small funnel and a base with adjustable angle. This concept of design is similar to the ideal model method. The sand sample is considered to be made up of extremely fine granular materials. Keeping the granule state is 
chaos and disordered, and putting them into an inclined device.

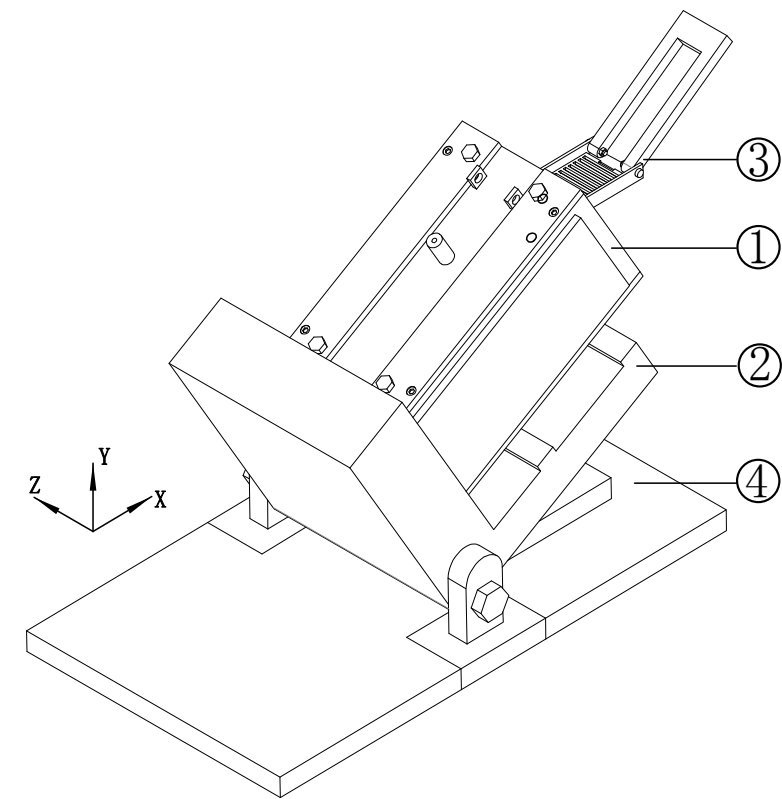

1. A TRANSPARENT BUCKET 2. A BASE WITH ADJUSTABLE ANGLE 3. A SMALL FUNNEL 4. A SUPPORTING BASE

FIGURE IV. A NOVEL DEVICE OF TRUE TRIAXIAL APPARATUS FOR MAKING LAYERED SAND SPECIMEN

The characteristic of the device is that the adjustable angle bracket is assembled on the support base, the transparent bucket is installed on the adjustable angle bracket and the small funnel can reach inside of the transparent bucket. Turning the adjustment angle bracket can achieve different inclination angles. The adjustable angle bracket is machined with a groove and the transparent bucket is assembled on the groove.

During the sample preparation, the size of sand sample is still $75 \mathrm{~mm} * 75 \mathrm{~mm} * 150 \mathrm{~mm}$. The transparent bucket is the key component to the sample preparation device. As shown in Figure 5 , it consists of four detachable fixed plates, that two fixed plate are made of alloy steel, and the other two transparent fixed plates are made of plexiglass material. It is clear to observe the process of sand sample preparation in the transparent bucket. There is a interlayer of water injection glued on the outer wall of the plexiglass plate, and the top of the water injection interlayer is machined with water injection hole, and opening the connected pipe mouth at the bottom, and the pipe connects the two pipe mouths of the two water injection interlayers, so that the horizontal surface on the both sides of the interlayer always keep in the same height. In the process of preparing sand sample, this design can improve the accuracy of sand sample delamination by the rise of the water surface. At the same time, the funnel includes a rocking handle and two shims with gate holes. During the operation, the funnel, which is filled with sand, is placed horizontally into the transparent bucket, then lightly jitter, sand can be naturally dropped by its own weight and avoid disturbance to the sand sample.

In order to ensure the integrity and rigorousness of the device during the operation, four tapping holes with auxiliary disassembly function are welded on the bucket to disassemble easily. After the specimen is finished, when the fixed plate is disassembled, the shape of the sand sample will not be damaged due to excessive force.

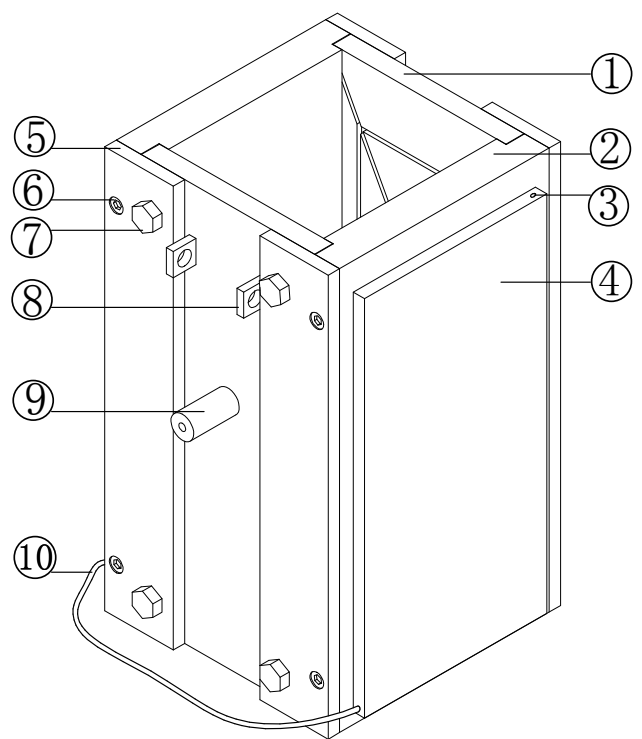

1. METAL FIXED PLATE 2. TRANSPARENT FIXED PLATE 3. WATER INJECTION HOLE 4. WATER INJECTION INTERLAYER 5. METAL SPLINT 6. NUT 7. HEXAGON NUT 8. TAPPING HOLE 9. PUMP-LINE 10 PIPE

\section{FIGURE V. A TRANSPARENT BUCKET}

The innovative points of the design also include the two plates of alloy steel are designed with two "X" shaped paths to increase the vacuum suction area. In addition, the telescopic supporting rod is provided with an angle converter, which is the same as the inclination of the experimental demand, they are $15,30,45,60$, and 75 degrees. They can make the device stable in the preparation of the sand sample.

\section{CONCLUSIONS}

(1) The true triaxial apparatus is a very important instrument for researching the constitutive relation of sand, and the improvement of the sand sample preparation device can extend the scope to the true triaxial test.

(2) The preparation quality of the true triaxial sand sample is the prerequisite to determine whether the true triaxial test is smooth, and the making of the sand sample with different deposition angles can provide a guarantee for researching the constitutive relation of the true triaxial test.

(3) The principle of making the true triaxial sand sample is very simple, but due to the heterogeneity and anisotropy of sand, it is more difficult to prepare sand sample with different deposition angles. The design of the sand sample preparation device and the researching of the making process of specimen, which need to be further researched.

\section{ACKNOWLEDGMENT}

This work was financially supported by the National Natural Science Foundation of China (NO:5168050, NO:51669027) and the National Key R\&D Program of China 
(2017YFC0504400, 2017YFC0504404). These supports are gratefully acknowledged.

\section{REFERENCES}

[1] B. Kou, Y. Cao. "Granular materials flow like complex fluids. " Nature 551.7680(2017).

[2] Z. Cheng, and J. F. Wang. "Miniature three axis test instrument for testing the micro mechanical behavior of granular soil." Rock and Soil Mechanics 3 (2018).

[3] C. G. Zhang. " Research Progress on true three axis test of unsaturated soil." Mechanics in Engineering 36.4(2014) , pp. 271-350.

[4] R. Makhnenko, and J. Labuz. "Plane Strain Testing with Passive Restraint." Rock Mechanics \& Rock Engineering 47.6(2014), pp. 2713502021-2029.

[5] S. J. Shao. " Development and development of a new true three axis instrument." Chinese Journal of Geotechnical Engineering 31.8(2009), pp. 1172-1179.

[6] S. Wei. "Three axis experimental study on steady state strength, consolidation and undrained of sand." Chinese Journal of Rock Mechanics and Engineerin 24.22 (2005), pp. 4151-4157.

[7] Weinhart, Thomas. "Coarse-grained local and objective continuum description of three-dimensional granular flows down an inclined surface." Physics of Fluids 25.7(2013), pp. 41-47.

[8] S. E. Ostojic, Somfai, and B. Nienhuis. "Scale invariance and universality of force networks in static granular matter. " Nature 439.7078(2006), pp. 828-830.

[9] H. J. Hu. " Preliminary study on the effect of sample preparation method on uniaxial tensile strength of remolded loess." Rock and Soil Mechanics 30.s2(2009), pp.205-208.

[10] F. L. Kong, and S. Y. Zhang. "Preparation of three axial specimens of fill." Hydropower and pumped storage 4(1981), pp.53-56.

[11] T. F. Gu. " A cutting instrument for preparing undisturbed loess samples for three axis tests.", CN102169062A. 2011.

[12] H. Yang. " Method and verification of three axis test for quickening suction balance." Advances in Mechanics 48.1(2018).

[13] Z. Chen. "Effect of sampling method on the results of static three axis test for saturated medium sand." Diss. Journal of Dalian University of Technology, 2010.

[14] M. Sha. and C. G. Zhao "Effect of specimen size and sample size on shear strength of coarse grained soil in three axial tests." Journal of Beijing Jiaotong University 38.4(2014) , pp.133-136.

[15] Y. Z. Tan. " Measurement of particle movement and structure in dense granular systems." Journal of Hydraulic Engineering S2 (2014), pp.3138.

[16] H. Yang. " Measurement of particle movement and structure in dense granular systems." Advances in Mechanics 48.1(2018). 